\title{
Atribuições causais para o sucesso e fracasso escolares
}

\section{Causal attributions for academic success and failure}

\author{
Leandro da Silva ALMEIDA \\ Lúcia MIRANDA \\ María Adelina GUISANDE²
}

\begin{abstract}
Resumo
A Teoria da Atribuição de Causalidade representa um interessante corpo teórico para analisar como os alunos explicam as suas situações de sucesso e de insucesso escolar. Este artigo analisa se essas atribuições causais se diferenciam de acordo com o gênero e o ano escolar dos alunos. A amostra foi composta por 868 alunos do $5^{\circ}$ ao $9^{\circ}$ ano de escolaridade. A avaliação recorreu ao Questionário de Atribuições de Resultados Escolares, no qual os alunos ordenam seis causas possíveis (esforço, método de estudo, bases/conhecimentos, ajuda dos professores, sorte e capacidade) consoante a sua importância na explicação dos seus sucessos e dos seus insucessos escolares. Os resultados sugerem que os alunos, independentemente do sexo e do ano escolar, associam os seus resultados acadêmicos (sucesso e fracasso) ao esforço, surgindo ainda para explicar o insucesso a falta de métodos apropriados de estudo. À medida que se avança na escolaridade, as bases de conhecimentos surgem mais valorizadas na explicação do sucesso escolar. Por outro lado, os rapazes parecem recorrer mais à capacidade para explicar o seu sucesso, e as meninas mais ao esforço e às bases de conhecimentos. Na explicação do insucesso, a falta de esforço e de método de estudo surgem mais valorizados que a capacidade conforme se avança na escolaridade, o que parece proteger a auto-estima dos alunos.
\end{abstract}

Unitermos: Aprendizagem escolar. Motivação. Rendimento escolar.

\begin{abstract}
The causal attribution theory represents an interesting theoretical framework in which to analyze how students explain their academic success or failure. This paper analyzes if the causal attributions are different according to gender and school grade. The sample comprised 868 students from $5^{\text {th }}$ to $9^{\text {th }}$ grade. The evaluation of the attributions was conducted by means of a school results Attribution Questionnaire (known in Brazil as QARE), in which students rank six possible causes (effort, studying methods, academic background, teacher support, luck and ability) according to their importance in explaining personal academic successes and failures. The data suggest that students, regardless of gender and grade, related their academic achievement (success and failure) to effort, citing poor studying methods as a secondary reason to explain academic failure. Progressing through the school system, the academic knowledge base becomes more important when explaining success at school. On the other hand, male students resort more to ability to explain their academic success, while female students cite effort and existing academic knowledge. For the explanation of failure at school, effort and studying methods are more significant than lack of ability as their education progresses, which seems to reinforce the students' self-esteem.
\end{abstract}

Uniterms: School learning. Motivation. Academic achievement.

$\boldsymbol{\nabla \nabla \nabla \nabla}$

1 Universidade do Minho, Instituto de Educação e Psicologia, Departamento de Psicologia. Campus de Gualtar, 4710, Braga, Portugal. Correspondência para/Correspondence to: L.S. ALMEIDA. E-mail: <leandro@iep.uminho.pt>.

2 Universidade de Santiago de Compostela, Faculdade de Psicologia, Departamento de Psicologia Evolutiva e Educação. Santiago de Compostela, Espanha. 
Na longa tradição da psicologia cognitiva, o ser humano formula percepções e avaliações sobre os seus comportamentos e desempenhos (Heider, 1944), buscando também uma explicação para os níveis de rendimento atingidos. Na escola, em particular, os alunos vão desenvolvendo justificativas que os ajudam a interpretar os seus melhores e mais fracos resultados acadêmicos. No quadro da Teoria da Atribuição de Causalidade (Weiner, 1979, 1988), interessou a este estudo, particularmente, as explicações encontradas para os resultados de maior ou menor sucesso na aprendizagem escolar, assumindo que as mesmas se estruturam e afetam os comportamentos, cognições e emoções dos alunos ao longo da sua escolaridade (Almeida et al., 2006; Barros, 1996; Barros, Barros \& Neto, 1993; Fernández, 2005; Santos, 1989).

Tomando a diversidade de explicações que os alunos invocam para explicar o seu sucesso e fracasso na escola, Weiner $(1986,1988)$ organiza-as em seis fatores: 1) capacidade, que reflete o grau em que considera as suas próprias habilidades e aptidões como relevantes para a realização da tarefa; 2) esforço, que reflete a intensidade e energia que o sujeito imprime para levar a cabo uma determinada tarefa; 3) estratégias, que se refere aos diferentes processos e métodos que o sujeito implementa para melhorar os seus resultados na aprendizagem; 4) tarefa, que diz respeito à dificuldade ou facilidade das tarefas escolares; 5) professores, que se relaciona com a percepção do papel que o professor assume no rendimento do aluno, por exemplo, em função das suas características de personalidade e de destrezas profissionais; e 6) sorte, que expressa o peso que o aluno atribui ao azar ou à sorte nos seus desempenhos acadêmicos.

Em uma tentativa de sistematização desta multiplicidade de causas, Weiner $(1986,1988)$ distingue-as entre causas internas e externas (localização dentro e fora da pessoa); entre causas estáveis e instáveis (que permanecem relativamente constantes ou variáveis ao longo do tempo); e, finalmente, entre causas controláveis e incontroláveis (que estão sob o controle ou fora do controle da vontade do sujeito). Posteriormente, acrescenta-se, ainda, serem causas mais gerais ou específicas, por exemplo, generalizáveis a todas as situações curriculares ou apenas para determinadas disciplinas do currículo. Com esta taxonomia presente, pode-se inferir que a capacidade pode ser entendida como uma causa 170 interna, estável e fora do controle do sujeito; o esforço e as estratégias são vistos como causas internas, mas instáveis e controláveis pelo sujeito; e, tanto a dificuldade da tarefa, como a sorte e o professor, são vistos como causas externas, instáveis e fora do controle do indivíduo (Fernández, 2005).

As atribuições causais têm conseqüências, tanto para as expectativas de sucesso e de fracasso futuro, como para o auto-conceito e a auto-estima dos alunos (Barros, 1996; González-Pienda et al., 2000; Weiner, 1979, 1986). As dimensões de causalidade e as crenças individuais responsáveis pelos sucessos e fracassos escolares desempenham um importante papel no rendimento subseqüente do aluno, nas emoções e na própria motivação para a aprendizagem. Logicamente que estas atribuições, a sua diferenciação entre os alunos e a própria importância que assumem em cada aluno refletem as experiências anteriores de aprendizagem e de desempenho, marcando igualmente as suas experiências futuras (Barca \& Peralbo, 2002; Barros, 1996; Fernandéz, 2005; Ramírez \& Ávila, 2002; Torres, 1999; Weiner, 1979, 1986). Por exemplo, os alunos sentem orgulho após um sucesso, se a tarefa for atribuída a uma causa interna. Por outro lado, poderão sentir vergonha se uma causa interna for responsável por um fracasso. Assim, os alunos que tendem a explicar os fracassos a partir de características pessoais estáveis e generalizadas acabam por apresentar um estilo atribucional pessimista, definido na literatura como desânimo aprendido (Seligman, 1975), geralmente associado a fracas estratégias de estudo e aprendizagem, a baixas classificações e a menores níveis de aspiração (Barros \& Almeida, 1991; Barros, Neto \& Barros, 1992; Fernández, 2005).

Em uma lógica de manutenção da auto-estima positiva, alguns alunos atribuem os seus fracos resultados acadêmicos a fatores externos (Branscombe \& Wann, 1994). Quando essa estratégia defensiva não pode ser prolongada, alguns estudantes invertem o valor da situação crítica, por exemplo, organizam-se em torno de uma cultura anti-institucional, em que se valoriza precisamente o "ser mau" na escola ou se apresenta comportamentos característicos do estatuto adulto (ingestão de bebidas alcoólicas, fumar, ter relações sexuais etc.) (Peixoto, 2003; Robinson \& Breslav, 1996; Robinson, Tayler, \& Piolat, 1990; Senos, 1997). Na mesma linha, Kaplan H.B. e Lin (2000) e Kaplan D.S., Pecke Kaplan H.B. (1994) referem que uma das formas de os alunos lidarem com o insucesso acadêmico pode passar pela 
desvalorização da fonte desse insucesso, isto é, a escola, para desse modo permitir a manutenção de uma auto-estima positiva. Por outro lado, outros estudos revelam que essa proteção da auto-estima pode ser conseguida a partir de uma reorganização do auto-conceito, em que a área ameaçadora (neste caso, a acadêmica) é desinvestida pelo aluno, passando o mesmo, a investir em áreas potencialmente mais gratificantes, por exemplo, o auto-conceito físico, quando em situação de fracasso escolar (Peixoto, 2003; Senos, 1997).

A associação entre aprendizagem, rendimento e atribuições está longe de poder ser assumida como simples e linear. Pelo contrário, a investigação tem explicitado um conjunto de enviezamentos na formulação de tais percepções pelos alunos. Barros e Barros (1993), em um estudo em Portugal, referem uma assimetria entre algumas causas dadas para explicar o sucesso e o insucesso, deixando antever a hipótese da existência de um padrão atribucional ego-defensivo, referido nas investigações como erro atribucional ou viés atribucional em benefício próprio. Mais concretamente, os alunos aprendem a assumir a responsabilidade pelos seus sucessos e a rejeitar a responsabilidade pelos seus insucessos (Barros, 1996; Fernández, 2005).

A investigação na área das atribuições causais sugere que estas se diferenciam em função do gênero e do ano de escolaridade dos alunos. Em uma análise da literatura, as alunas poderão classificar as suas habilidades e a própria capacidade mais negativamente, demonstrando baixa expectativa de sucesso e maior recurso a fatores externos para explicar os seus sucessos acadêmicos (Martini \& Del Prette, 2005). Por outro lado, os rapazes tendem a atribuir menos o fracasso à capacidade intelectual, preservando o seu próprio autoconceito (Martini \& Del Prette, 2005; Neves, 2002; Schlieper, 2001). Em um estudo transcultural, Ferreira et al. (2002) sugerem que os adolescentes atribuem o sucesso mais à capacidade, e as adolescentes mais ao esforço. No entanto, em muitos outros estudos, os valores obtidos não se diferenciaram de acordo com o gênero dos alunos (Barca \& Peralbo, 2002; Barros et al., 1992; Mascarenhas, Almeida \& Barca, 2005).

Relativamente ao ano de escolaridade dos alunos, variável também associada à idade e ao desenvolvimento psicológico, alguns estudos apontam diferenças nas atribuições causais para o sucesso e para o fracasso que se diferenciam ao longo da escolaridade (Barca, Peralbo \& Cadavid, 2003; Fernández, 2005;
Gonzaga, Morais, Santos \& Jesus, 2006). Por exemplo, os alunos mais novos valorizam mais o método ou a própria pessoa do professor, ao mesmo tempo que o recurso a causas internas para explicar o sucesso e o fracasso escolar aumenta com a escolaridade (Faria, 1998; Gonzaga et al., 2006; Ramirez \& Ávila, 2002).

Com este estudo, pretendeu-se analisar os estilos atribucionais de uma amostra de alunos portugueses do Ensino Básico na explicação do seu sucesso e fracasso escolar, e verificar se tais estilos atribucionais se diferenciam em função de algumas variáveis dos alunos, tais como o gênero e o ano de escolaridade.

\section{Método}

\section{Participantes}

A amostra foi formada por alunos do $5^{\circ}$ ao $9^{\circ}$ ano de escolaridade do ensino público de quatro escolas do distrito do Porto, sendo constituída por 868 alunos (162 alunos do 50; 175 do 60; 161 do 70; 204 do 80; e 166 do $9^{\circ}$ ano de escolaridade). Destes alunos, 46,3\% (402) eram do sexo masculino e $53,7 \%$ (466), do sexo feminino. As idades oscilaram entre os nove anos (dois alunos) e os 17 (quatro alunos), situando-se a média em 12,8 (desvio-padrão - DP=1,63). Relativamente ao nível de escolaridade dos pais e encarregados de educação, a maioria detinha apenas quatro anos de escolaridade $(51,7 \%)$, e apenas $4,3 \%$ freqüentaram um curso de ensino superior (esta situação aplica-se às mães e aos pais, havendo apenas um pequeno aumento para 5,9\%, no caso das mães).

\section{Instrumentos}

Para este estudo, foi utilizado o Questionário de Atribuições de Resultados Escolares (QARE) (Almeida \& Miranda, 2005). Este instrumento avalia as atribuições causais para o sucesso e insucesso em duas situações: resultados nos testes e notas escolares em geral. Para cada uma destas situações de sucesso ou fracasso, apresentam-se seis justificativas ou causas possíveis (esforço, método de estudo, bases/conhecimentos, ajuda dos professores, sorte e capacidade), devendo o aluno hierarquizar as mesmas por ordem crescente de importância (ranking scale). Dada a forma como foi constituída a prova, uma baixa pontuação sugere que essa causa é colocada em primeiro lugar, ou assumida como mais importante, e vice-versa. 


\section{Procedimentos}

Este questionário foi aplicado às turmas durante tempo letivo cedido pelos professores. Salientou-se aos alunos que os resultados se destinavam a uma investigação, justificando a necessidade da sinceridade nas suas respostas. Não havendo boas e más respostas, pedia-se a leitura sempre das seis causas possíveis e a sua ordenação progressiva. As análises estatísticas foram realizadas com o programa estatístico SPSS (Versão 15,0).

\section{Resultados}

Na Tabela 1, constam os resultados das ordenações pelos alunos das seis causas facultadas para a explicação do seu sucesso escolar, apresentando os valores médios e o desvio-padrão entre parênteses. Como se pode verificar, de um modo geral os alunos explicam os seus sucessos escolares recorrendo, sobretudo, ao esforço e às suas bases de conhecimentos, aparecendo em último lugar nas ordenações a falta de sorteoua capacidade.Contudo, observa-se alguma dispersão nas respostas consoante as variáveis gênero e ano escolar. Assim, à medida que se avança no ano de escolaridade, observa-se um maior distanciamento nas médias entre rapazes e meninas, no que diz respeito à atribuição dos seus sucessos escolares ao esforço, por exemplo.

Para uma apreciação da significância estatística das diferenças observadas nas ordenações das causas explicativas do sucesso escolar, considerando os alunos em função do ano escolar e do gênero, realizou-se uma análise de variância multivariada (F-Manova 5 × 2).

Os resultados obtidos sugerem um efeito significativo da interação do ano escolar com o gênero nas atribuições do sucesso ao esforço $[F(4,867)=4,441$, $\left.p<0,001, \eta^{2}=0,020\right]$, à sorte $[F(4,867)=2,716, p<0,05$, $\left.\eta^{2}=0,013\right]$ e ao método de estudo $[F(4,867)=4,701$, $\left.p<0,001, \eta^{2}=0,021\right]$. Conforme se pode visualizar na Figura 1 , rapazes e meninas no 50,60 e $7^{\circ}$ anos tendem a valorizar da mesma forma o esforço na explicação dos seus bons resultados escolares (aliás, ambos reforçam essa importância no 70 ano), contudo, os dois gêneros afastam-se no $8^{\circ}$ e $9^{\circ}$ anos, devido a uma menor valorização do esforço pelos rapazes. Por sua vez, na Figura 2, observa-se que os alunos dos dois gêneros estão bastantes próximos na atribuição dos bons resultados à sorte (aliás, as meninas reforçam essa valorização no $6^{\circ}$ ano), passando então a sorte a ser menos valorizada pelas meninas, diferença essa que se acentua olhando os valores no 90 ano de escolaridade. Finalmente, na Figura 3, pode-se entender o efeito da interação do ano escolar com gênero na atribuição do bons resultados ao método de estudo. Com efeito, também aqui os alunos dos dois gêneros estão muito próximos na valorização deste fator no $5^{\circ}$ e $6^{\circ}$ anos, passando então o método a ser mais valorizado pelas meninas, diferença essa que se acentua olhando os valores no 70 e no $90^{\circ}$ ano de escolaridade.

Verificaram-se ainda efeitos principais, segundo o gênero dos alunos, nas atribuições do sucesso acadêmico à capacidade $[F(1,867)=15,238, p<0,001$, $\left.\eta^{2}=0,017\right]$, traduzindo que os rapazes $(M=8,10, D P=0,13)$ recorrem mais à capacidade do que as meninas $(M=8,80$, $D P=0,12)$ na explicação dos respectivos sucessos. Considerando o ano escolar, observaram-se diferenças estatisticamente significativas na atribuição do sucesso às bases de conhecimentos $[F(4,867)=2,764, p<0,05$,

Tabela 1. Ordenação média (M) e desvio-padrão (DP) das causas atribucionais para o sucesso por ano escolar e gênero dos alunos. Distrito de Porto, Portugal.

\begin{tabular}{|c|c|c|c|c|c|c|c|c|c|c|c|c|c|c|c|}
\hline & \multirow{2}{*}{ Ano } & \multirow{2}{*}{ Sexo } & \multirow{2}{*}{$\mathrm{n}$} & \multicolumn{2}{|c|}{ Esforço } & \multicolumn{2}{|c|}{ Bases } & \multicolumn{2}{|c|}{ Ajuda prof. } & \multicolumn{2}{|c|}{ Sorte } & \multicolumn{2}{|c|}{ Capacidade } & \multicolumn{2}{|c|}{ Método estudo } \\
\hline & & & & $M$ & DP & $M$ & $\mathrm{DP}$ & $M$ & DP & $M$ & $\mathrm{DP}$ & $M$ & $\mathrm{DP}$ & M & $\mathrm{DP}$ \\
\hline & $5^{\circ}$ & M & 81 & 4,72 & 2,64 & 5,72 & 2,03 & 6,07 & 2,42 & 9,46 & 2,51 & 8,21 & 2,56 & 6,47 & 2,33 \\
\hline \multirow{6}{*}{ 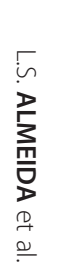 } & & $\mathrm{F}$ & 81 & 4,60 & 2,43 & 5,81 & 2,14 & 5,78 & 2,50 & 9,02 & 2,48 & 8,22 & 2,72 & 6,64 & 1,93 \\
\hline & $6^{\circ}$ & M & 93 & 4,82 & 2,83 & 5,78 & 2,11 & 6,47 & 2,43 & 9,02 & 2,82 & 8,13 & 2,78 & 6,58 & 2,06 \\
\hline & & $\mathrm{F}$ & 82 & 4,62 & 2,87 & 6,24 & 1,89 & 5,72 & 2,62 & 8,50 & 2,86 & 8,74 & 2,81 & 6,37 & 2,15 \\
\hline & 70 & M & 71 & 4,41 & 2,51 & 5,68 & 1,98 & 6,45 & 2,37 & 9,04 & 2,50 & 8,15 & 2,55 & 6,99 & 2,42 \\
\hline & & $\mathrm{F}$ & 90 & 4,04 & 2,43 & 6,18 & 1,68 & 6,03 & 2,35 & 8,68 & 2,55 & 8,99 & 2,38 & 5,80 & 2,13 \\
\hline & $8^{\circ}$ & M & 93 & 4,46 & 2,78 & 5,56 & 1,77 & 6,35 & 2,19 & 10,05 & 2,46 & 8,08 & 2,52 & 6,00 & 2,26 \\
\hline 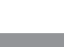 & & $\mathrm{F}$ & 111 & 3,55 & 1,99 & 5,31 & 1,65 & 6,77 & 2,35 & 10,40 & 2,36 & 8,77 & 2,46 & 5,13 & 1,71 \\
\hline & $9^{\circ}$ & M & 64 & 5,91 & 3,14 & 5,92 & 2,10 & 6,41 & 2,80 & 8,20 & 2,80 & 7,91 & 2,89 & 7,14 & 2,77 \\
\hline & & $F$ & 102 & 3,70 & 2,47 & 5,42 & 1,42 & 6,51 & 2,10 & 9,24 & 2,56 & 9,25 & 2,52 & 5,48 & 2,06 \\
\hline
\end{tabular}




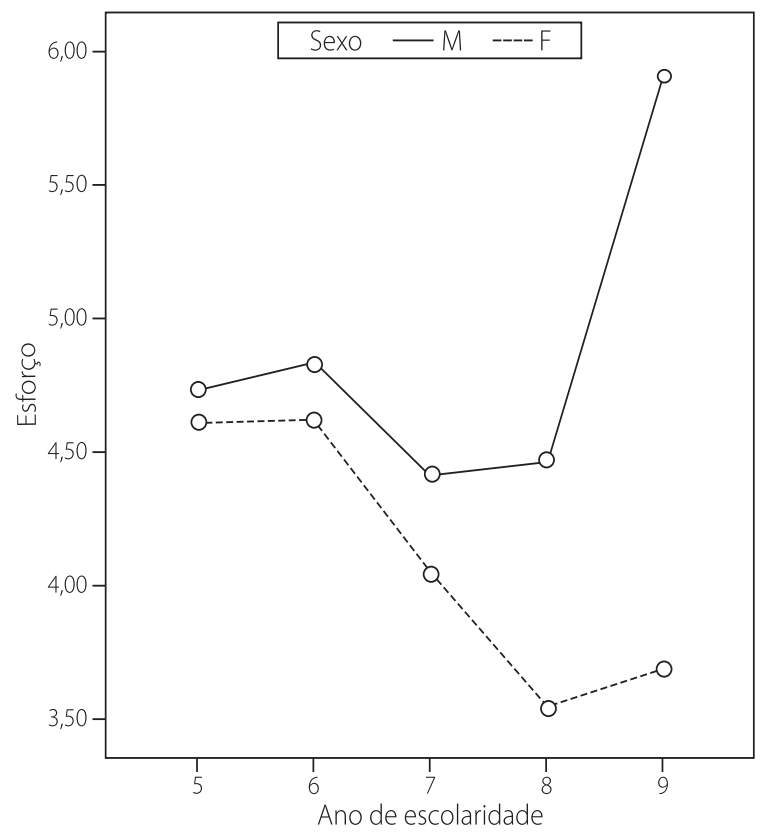

Figura 1. Interação do ano de escolaridade com o gênero dos alunos na atribuição do sucesso ao esforço. Distrito de Porto, Portugal.

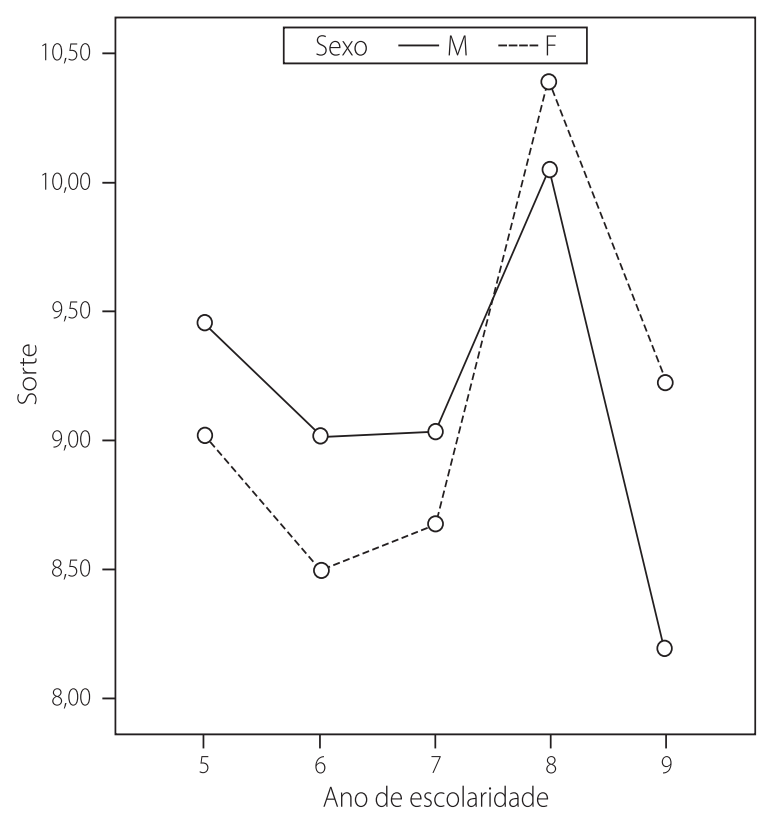

Figura 2. Interação do ano de escolaridade com o gênero dos alunos na atribuição do sucesso à sorte. Distrito de Porto, Portugal.

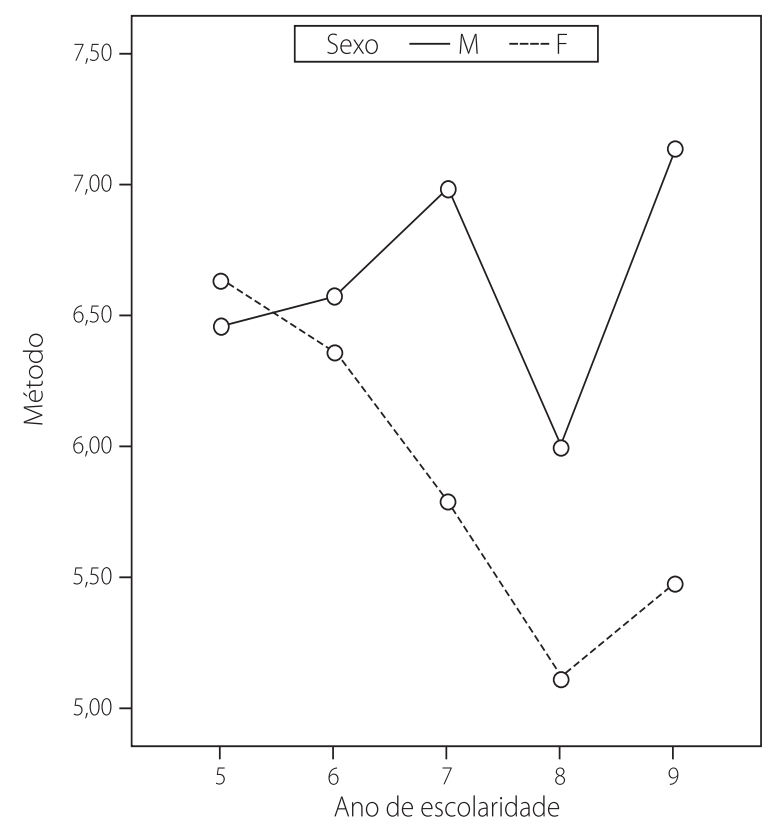

Figura 3. Interação do ano de escolaridade com o gênero dos alunos na atribuição do sucesso ao método de estudo. Distrito de Porto, Portugal.

$\left.\eta^{2}=0,013\right]$. Neste caso concreto, os alunos do $8^{\circ}$ ano acabam por atribuir mais o seu sucesso às bases de conhecimentos do que os colegas do $6^{\circ}$ ano (diferença de média $=-0,58 ; p<0,01$ ) e do 70 ano (diferença de média $=-0,494 ; p<0,05)$.

Na Tabela 2, constam as ordenações dos alunos para os fatores explicativos do seu insucesso escolar. De uma maneira geral, os alunos tendem a explicar os seus insucessos escolares mencionando a falta de esforço e a falta de métodos apropriados de estudo. Em último lugar, os fracassos escolares aparecem associados à falta de capacidade e à falta de ajuda do professor, registrando-se também algumas oscilações segundo o gênero e o ano escolar. Por exemplo, os alunos do $5^{\circ}$, do $6^{\circ}$ e do $8^{\circ}$ ano de escolaridade explicam os seus insucessos, sobretudo, pela falta de esforço. Finalmente, no $9^{\circ}$ ano de escolaridade, os rapazes justificam os seus insucessos com a falta de esforço, e as meninas recorrem à falta de método de estudo.

$\mathrm{Na}$ apreciação estatística das oscilações verificadas nas atribuições que os alunos realizam para os seus insucessos escolares, tomando o ano e o gênero (F-Manova 5 × 2), não se verificou qualquer efeito estatisticamente significativo de interação das variáveis independentes em presença. Em termos de efeitos principais, há diferenciação das atribuições do fracasso ao método de estudo $\left[F(1,867)=9,861, p<0,01, \eta^{2}=0,011\right]$ 
Tabela 2. Ordenação média (M) e desvio-padrão (DP) das causas atribucionais para o insucesso por ano escolar e gênero dos alunos. Distrito de Porto, Portugal.

\begin{tabular}{|c|c|c|c|c|c|c|c|c|c|c|c|c|c|c|}
\hline \multirow[t]{2}{*}{ Ano } & \multirow[t]{2}{*}{ Sexo } & \multirow[t]{2}{*}{$\mathrm{n}$} & \multicolumn{2}{|c|}{ Falta de esforço } & \multicolumn{2}{|c|}{ Falta de bases } & \multicolumn{2}{|c|}{$\begin{array}{c}\text { Falta de ajuda } \\
\text { professor }\end{array}$} & \multicolumn{2}{|c|}{ Falta de sorte } & \multicolumn{2}{|c|}{$\begin{array}{c}\text { Falta de } \\
\text { Capacidade }\end{array}$} & \multicolumn{2}{|c|}{$\begin{array}{c}\text { Falta de método } \\
\text { estudo }\end{array}$} \\
\hline & & & $M$ & DP & M & DP & M & DP & M & $\mathrm{DP}$ & M & DP & M & DP \\
\hline \multirow[t]{2}{*}{$5^{\circ}$} & M & 81 & 5,16 & 2,76 & 6,67 & 1,70 & 9,20 & 2,65 & 7,06 & 2,37 & 7,56 & 2,66 & 6,36 & 2,61 \\
\hline & $F$ & 81 & 5,52 & 2,86 & 6,91 & 1,89 & 8,95 & 2,54 & 6,85 & 2,56 & 7,68 & 2,75 & 6,01 & 2,64 \\
\hline \multirow[t]{2}{*}{$6^{\circ}$} & $M$ & 93 & 4,99 & 3,29 & 6,88 & 2,25 & 7,71 & 2,94 & 7,69 & 2,54 & 8,03 & 2,75 & 6,72 & 2,03 \\
\hline & $\mathrm{F}$ & 82 & 4,62 & 2,24 & 6,65 & 2,14 & 8,54 & 3,21 & 7,30 & 2,31 & 8,34 & 2,84 & 6,60 & 2,60 \\
\hline \multirow[t]{2}{*}{70} & M & 71 & 5,55 & 3,07 & 7,51 & 2,10 & 8,13 & 2,76 & 7,11 & 2,73 & 8,62 & 2,90 & 5,51 & 2,40 \\
\hline & $\mathrm{F}$ & 90 & 5,74 & 3,02 & 7,33 & 1,86 & 8,63 & 2,96 & 6,77 & 2,47 & 8,63 & 2,79 & 4,92 & 2,47 \\
\hline \multirow[t]{2}{*}{$8^{\circ}$} & M & 93 & 4,96 & 3,04 & 6,66 & 2,01 & 8,33 & 2,52 & 7,65 & 2,71 & 8,42 & 3,24 & 5,89 & 2,23 \\
\hline & $\mathrm{F}$ & 111 & 4,64 & 2,54 & 6,60 & 2,00 & 8,41 & 2,64 & 7,95 & 2,49 & 8,96 & 2,53 & 5,45 & 2,09 \\
\hline \multirow[t]{2}{*}{$9^{\circ}$} & M & 64 & 4,53 & 2,70 & 7,09 & 2,19 & 9,00 & 2,38 & 6,30 & 2,74 & 9,41 & 2,52 & 5,64 & 2,20 \\
\hline & $\mathrm{F}$ & 102 & 5,14 & 2,82 & 6,55 & 1,83 & 9,22 & 2,38 & 7,08 & 2,69 & 9,38 & 2,57 & 4,62 & 2,13 \\
\hline
\end{tabular}

entre os gêneros. Assim, as meninas ( $M=5,5, D P=0,11)$ recorrem mais ao método de estudo do que os rapazes $(M=6,0, D P=0,12)$ para explicar as suas situações de insucesso.

Por sua vez, considerando a variável ano escolar, observam-se diferenças com significado estatístico na atribuição do fracasso escolar ao esforço $[F(4,867)=3,096$, $\left.p<0,05, \eta^{2}=0,014\right]$, às bases $[F(4,867)=3,961, p<0,01$, $\left.\eta^{2}=0,018\right]$, ao professor $[F(4,867)=4,592, p<0,001$, $\left.\eta^{2}=0,021\right]$, à sorte $\left[F(4,867)=5,673, p<0,001, \eta^{2}=0,026\right]$, à capacidade $\left[F(4,867)=9,154, p<0,001, \eta^{2}=0,041\right]$ e ao método de estudo $\left[F(4,867)=12,892, p<0,001, \eta^{2}=0,057\right]$.

Relativamente ao esforço, os alunos do 70 ano recorrem menos a este para explicar os seus insucessos escolares, face aos colegas do $6^{\circ}$ ano (diferença de média $=0,841, p<0,01$ ), do $8^{\circ}$ ano (diferença de média $=0,849$, $p<0,01$ ) e do $9^{\circ}$ ano (diferença de média $=0,813, p<0,05$ ).

Em relação à atribuição do insucesso escolar às bases de conhecimentos, os alunos do 70 ano acabam por valorizar menos esta explicação que os colegas do $5^{\circ}$ ano (diferença de média $=0,630, p<0,01$ ), $6^{\circ}$ ano (diferença de média $=0,656, p<0,01$ ), $8^{\circ}$ ano (diferença de média $=0,790, p<0,001$ ) e $9 \circ$ ano (diferença de média $=0,599, p<0,01)$.

Considerando a variável professor, os alunos do $5^{\circ}$ ano não o valorizam tanto na explicação dos seus insucessos, comparativamente aos colegas do $6^{\circ}$ ano (diferença de média $=0,951, p<0,001$ ), $70^{\circ}$ ano (diferença de média $=0,694, p<0,05$ ) e $8^{\circ}$ ano (diferença de média $=0,705, p<0,05$ ); verificando-se ainda que os alunos do $9^{\circ}$ ano recorrem menos ao professor para explicar os

174 seus fracassos que os alunos do $6^{\circ}$ ano (diferença de média $=0,985, p<0,001), 70$ ano (diferença de média $=0,728$, $p<0,05$ ) e $8^{\circ}$ ano (diferença de média $=0,738, p<0,05$ ). Relativamente à sorte, os alunos do $6^{\circ}$ ano recorrem menos à falta de sorte para explicar os seus insucessos escolares face aos colegas do 70 ano (diferença de média $=0,557, p<0,05$ ) e do $9^{\circ}$ ano (diferença de média $=0,809$, $p<0,01)$; observando-se esta mesma situação entre os alunos do $8^{\circ}$ ano em comparação com os alunos do $5^{\circ}$ ano (diferença de média $=0,839, p<0,01$ ), 70 ano (diferença de média $=0,856, p<0,01$ ) e $9^{\circ}$ ano (diferença de média=1,108, $p<0,001$ ).

Em relação à atribuição do insucesso escolar à capacidade, os alunos do $5^{\circ}$ ano acabam por valorizar mais esta explicação que os colegas do 70 ano (diferença de média $=-1,009, p<0,001$ ) e do $8^{\circ}$ ano (diferença de média $=-1,070, p<0,001)$; verificando-se ainda que os alunos do $9^{\circ}$ ano recorrem menos à capacidade para explicar os seus fracassos que os alunos do $5^{\circ}$ ano (diferença de média $=1,777, p<0,001$ ), $6^{\circ}$ ano (diferença de média $=1,207, p<0,001$ ), 70 ano (diferença de média $=0,768$, $p<0,05)$ e $8^{\circ}$ ano (diferença de média $=0,707, p<0,05$ ).

Finalmente, considerando o método de estudo, os alunos do $5^{\circ}$ ano não o valorizam tanto na explicação dos seus insucessos comparativamente aos colegas do 70 ano (diferença de média $=0,971, p<0,001$ ), do $8^{\circ}$ ano (diferença de média $=0,514, p<0,05$ ) e do $9^{\circ}$ ano (diferença de média=1,056, $p<0,001$ ). Da mesma forma, os alunos do $6^{\circ}$ ano também não valorizam tanto o método de estudo face aos colegas do 70 ano (diferença de média $=1,444, p<0,001$ ), do $8^{\circ}$ ano (diferença de média $=0,988$, $p<0,001$ ) e do $9^{\circ}$ ano (diferença de média $=1,530, p<0,001$ ), constatando-se, ainda, que os alunos do $8^{\circ}$ ano recorrem menos ao método de estudo para explicar os seus fra- 
cassos que os alunos do $9^{\circ}$ ano (diferença de média $=0,542, p<0,05)$.

\section{Discussão}

Com fundamento nas posições de Weiner (1979, 1986), e analisando-se de forma global os resultados obtidos, verifica-se que os alunos recorrem sobretudo a causas internas, em detrimento de causas externas, para explicar os seus sucessos e fracassos escolares. Assim, os alunos apontam o esforço como a causa mais valorizada, seja para explicar o sucesso, seja para explicar o fracasso escolar, desvalorizando nomeadamente a sorte na explicação do sucesso ou o professor na explicação do fracassos. Tendencialmente, este sentido geral dos resultados parece ocorrer independentemente do ano de escolaridade e do gênero dos alunos, como aliás ocorre em outros estudos, inclusive com alunos brasileiros (Boruchovitch, 2001; Boruchovitch \& Martins, 1997; Martini \& Del Prette, 2005; Mascarenhas et al., 2005; Neves, 2002). Segundo Weiner, quando o sujeito atribui o êxito ou o fracasso a causas estáveis, tenderá a gerar expectativas de que no futuro continuará a experimentar sucesso ou fracasso. No entanto, se as causas se consideram instáveis, tanto no caso do êxito como do fracasso, o sujeito terá dúvidas sobre o que irá acontecer futuro, pois tanto pode ocorrer um como o outro. Por outro lado, a atribuição do êxito e do fracasso a causas controláveis pelo sujeito, por exemplo, o esforço, produz motivação e persistência, o que contribui para aumentar o rendimento. Isso já não ocorre no caso de se justificar os resultados com fatores incontroláveis, por exemplo, o azar ou a sorte.

Para a explicação do sucesso escolar, ano e gênero dos alunos interagem na diferenciação das ordenações atribuídas ao esforço, à sorte e ao método de estudo. Os alunos mais novos valorizam da mesma forma o esforço e o método do estudo, independentemente do gênero. Contudo, nos mais velhos, observa-se uma menor valorização, por parte dos rapazes, de ambas as causas, a par de uma maior valorização da sorte (sobretudo no 90 ano). Por outro lado, e atendendo apenas ao gênero, os rapazes recorrem mais à capacidade para explicar o seu sucesso, ao mesmo tempo que, atendendo apenas ao ano escolar, as bases de conhecimentos aparecem progressivamente mais valorizadas na explicação do sucesso, à medida que se avança na escolaridade. Estes dados apontam para um maior compromisso pessoal por parte dos alunos no seu estudo e rendimento acadêmico à medida que avançam na escolaridade, sendo também certo que o próprio sistema apela progressivamente mais aos conhecimentos e destrezas acadêmicas adquiridas.

Em relação às explicações para o insucesso, as meninas recorrem mais à falta de um método de estudo mais adequado do que os rapazes. Relativamente ao ano escolar, observa-se nos alunos uma diminuição da referência à capacidade para explicarem o seu insucesso à medida que avançam na escolaridade; inversamente, valorizam progressivamente a falta de esforço e de método de estudo adequado. Este estilo atribucional parece ser mais defensivo de uma auto-estima positiva por parte do aluno (Peixoto, 2003; Robinson \& Breslav, 1996), preocupação que os professores e a escola devem considerar com devida atenção. Alunos mais fragilizados em termos de rendimento escolar devem ser ajudados pelos professores a lerem os seus sucessos e os seus fracassos mais numa lógica do método e volume de trabalho escolar do que na sua capacidade cognitiva. Como afirma Weiner (1986), para melhorar a motivação dos alunos é importante que estes saibam atribuir tanto os seus êxitos como fracassos ao nível de esforço envolvido na realização das tarefas, entendendo o esforço como uma causa interna, instável e controlável. Obviamente, enfatizando o esforço, os alunos acabam por aprender a valorizar o uso adequado de estratégias de aprendizagem, sempre necessárias ao sucesso em qualquer situação de aprendizagem e de realização acadêmica.

\section{Referências}

Almeida, L. S., \& Miranda, L. (2005). Questionário de atribuições de resultados escolares - QARE. Braga: Universidade do Minho.

Almeida, L. S., Miranda, L., Rosendo, A. P., Fernandes, E., Alves, J., \& Magalhães, R. (2006). Atribuições causais em contexto escolar: um novo formato de prova para a sua avaliação. In C. Machado, L. Almeida, M. A. Guisande, M. Gonçalves \& V. Ramalho (Orgs.), Actas da XI Conferência Internacional de Avaliação Psicológica: Formas e Contextos (pp.369-376). Braga: Psiquilíbrios.

Barca, A., \& Peralbo, M. (2002). Los contextos de aprendizajey desarrollo en la educación secundaria obligatoria (ESO). Perspectivas de intervención psicoeducativa sobre el fracaso escolar en la Comunidad Autónoma de Galicia. Madrid: Ministerio de Ciencia y Tecnología.

Barca, A., Peralbo, M., \& Cadavid, M. (2003). Atribuciones causales y rendimiento académico en alumnos de educación secundaria: un estudio a partir de la subescala 
de atribuciones causales y multiatribucionales (EACM). Psicologia: Teoria, Investigação e Prática, 1 (1), 17-30.

Barros, A. M. (1996). Atribuições causais e expectativas de controlo do desempenho na matemática. Tese de doutoramento não-publicada, Instituto de Educação e Psicologia, Universidade do Minho, Braga.

Barros, A. M., \& Almeida, L. S. (1991). Dimensões sócio-cognitivas do desempenho escolar. In L. S. Almeida (Ed.), Cognição e aprendizagem escolar (pp.87-97). Porto: APPORT.

Barros, A. M., \& Barros, J. H. (1993). Desempenho na matemática: atribuições causais dos alunos. Revista Portuguesa de Psicologia, 29 (1), 97-110.

Barros, A. M., Neto, F., \& Barros, J. H. (1992). Avaliação do locus de controlo e do locus de causalidade em crianças e adolescentes. Revista Portuguesa de Educação, 5 (1), 55-64.

Barros, J. H., Barros, A. M., \& Neto, F. (1993). Psicologia do controlo pessoal: aplicações educacionais, clínicas e sociais. Braga: Instituto de Educação e Psicologia, Universidade do Minho.

Boruchovitch. E. (2001). Conhecendo as crenças sobre inteligência, esforço e sorte de alunos brasileiros em tarefas escolares. Psicologia: Reflexão e Crítica, 14 (3), 461-467.

Boruchovitch, E., \& Martins, M. L. (1997). As atribuições de causalidade para o sucesso e fracasso escolar e a motivação para a aprendizagem de crianças brasileiras. Arquivos Brasileiros de Psicologia, 49 (1), 59-70.

Branscombe, N. R., \& Wann, D. L. (1994). Collective self-esteem consequences of out-group derogation when a valued social identity is on trial. European Journal of Social Psychology, 24 (6), 641-657.

Faria, L. (1998). Concepções pessoais de inteligência, atribuições e rendimento escolar. Psicologia, 12 (1), 101-113.

Fernández, A. G. (2005). Motivación académica: teoría, aplicación y evaluación. Madrid: Pirámide.

Ferreira, M. C., Assmar, E. M. L., Omar, A. G., Delgado, H. H., González, A. T., Souza, M. A., \& Cisne, M. C. F. (2002). Atribuição de causalidade ao sucesso e fracasso escolar: um estudo transcultural Brasil-Argentina-México. Psicologia: Reflexão e Crítica, 15 (3), 515-527.

Gonzaga, L., Morais, S., Santos, J., \& Jesus, S. N. (2006). Atribuições causais do sucesso e do fracasso académico: Estudo comparativo de estudantes do ensino secundário e do superior. In C. Machado, L. Almeida, M. A. Guisande, M. Gonçalves, \&V. Ramalho (Orgs.), Actas da XI Conferência Internacional de Avaliação Psicológica: Formas e Contextos (pp.951-960). Braga: Psiquilíbrios.

González-Pienda, J. A., Núñez, J. C., González-Pumariega, S., Álvarez, L., Roces, C., García, M., González, P., Cabanach, R. G., \&Valle A. (2000). Autoconcepto, proceso de atribución causal y metas académicas en niños con y sin dificultades de aprendizaje. Psicothema, 12 (4), 548-556.

Heider, F. (1944). Social perception and the phenomenal causality. Psychological Review, 51 (6), 358-374.

Kaplan, D. S., Peck, B. M., \& Kaplan, H. B. (1994). Structural and academic failure. Journal of Educational Research, 87 (3), 166-173

Kaplan, H. B., \& Lin, C. (2000). Deviant identity as a moderator of the relation between negative self-feelings and deviant behavior. Journal of Early Adolescence, 20 (2), 150-177.

Martini, M. L., \& Del Prette, Z. A. P. (2005). Atribuições de causalidade e afectividade de alunos de alto e baixo desempenho académico em situação de sucesso e de fracasso escolar. Revista Interamericana de Psicologia, 39 (3), 355-368.

Mascarenhas, S., Almeida, L. S., \& Barca, A. (2005). Atribuições causais e rendimento escolar: Impacto das habilitações escolares dos pais e do género dos alunos. Revista Portuguesa de Educação, 18 (1), 77-91.

Neves, L. F. (2002). Um estudo sobre as relações entre a percepção e as expectativas dos professores e dos alunos e o desempenho na matemática. Dissertação de mestrado. São Paulo: Universidade Estadual de Campinas. Disponível em http://www.des.emory.edu/mfp/das Neves.pdf

Peixoto, F. (2003). Auto-estima, autoconceito e dinâmicas relacionais em contexto escolar. Tese de doutoramento não-publicada, Universidade do Minho, Braga.

Ramírez, C. T., \& Ávila, A. G. (2002). Influencia de las atribuciones causales del profesor sobre el rendimiento de los alunos. Psicothema, 14 (2), 444-449.

Robinson, W. P., \& Breslav, G. (1996). Academic achievement and self-concept of Latvian adolescents in a changed social context. European Journal of Psychology of Education, 11 (4), 399-410.

Robinson, W. P., Tayler, C. A., \& Piolat, M. (1990). School attainment, self-esteem and identity. European Journal of Social Psychology, 20 (1), 1-17.

Santos, P. J. (1989). Classificação das atribuições e satisfação com os resultados escolares. Cadernos de Consulta Psicológica, 5 (1), 39-45.

Schlieper, M. D. M. J. (2001). Estratégias de aprendizagem e as atribuições de causalidade de alunos do ensino fundamental. Tese de mestrado. Recuperado em fevereiro de 2007, disponível em http:// libdigi.unicamp.br/ document/ ?code $=$ vtls000241375

Seligman, M. P. E. (1975). Helplessness. San Francisco: W. H. Freeman.

Senos, J. (1997). Identidade social, auto-estima e resultados escolares. Análise Psicológica, 15 (1), 123-137.

Torres, M. C. G. (1999). La motivación académica: Sus determinantes y pautas de intervención. Pamplona: EUNSA.

Weiner, B. (1979). A theory of motivation for some classroom experiences. Journal of Educational Psychology, 71 (1), 3-25.

Weiner, B. (1986). An attributional theory of motivation and emotion. New York: Springer-Verlag.

Weiner, B. (1988). Attribution theory in education. Revista Portuguesa de Educação, 1 (1), 21-25.

Recebido em: 7/8/2007

Versão final reapresentada em: 6/11/2007

Aprovado em: 13/12/2007 